Molecules 2001, 6, 1019-1020

molecules

ISSN 1420-3049

(C) 2001 by MDPI

http://www.mdpi.org

Book Received*

\title{
The Biotechnology of Ethanol: Classical and Future
} Applications. By M. Roehr (Editor). Wiley-VCH, Weinheim, July 2001. Pages: 244, Hardcover. Price: \$99.95. ISBN: 3-527-30199-2

Received: 1 December 2001

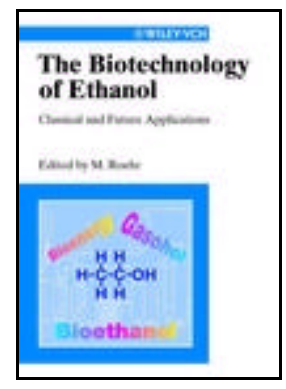

Focusing on the biotechnology of ethanol, this book highlights its industrial relevance as one of the most important products of primary metabolism. The text covers the most advanced developments among classical methods as well as more unconventional techniques, before going on to outline various aspects of new applications and the increasing importance of ethanol as a renewable resource. Topics covered in this unique volume include alternative raw materials, such as municipal waste and waste paper or particular crops, innovative methods of production using genetically engineered microorganisms, and the role of ethanol as both a source of energy and a valuable commodity.

The book is a valuable reference in that it combines biotechnological and economic aspects, while also providing an overview of the state of the art in the production and use of ethanol. Throughout, special emphasis has been placed on a balanced presentation between developments in Europe as well as in North and South America.

With contributions of T. Senn and H.J. Pieper and of N. Kosaric and F. Vardar-Sukan.

Table Of Contents:

Introduction (M. Roehr).

PART I.

CLASSICAL METHODS (T. Senn \& H. Pieper).

Starch Containing Raw Materials.

Technical Amylolysis. 
Starch Degradation by Autoamylolysis.

Mashing Processes.

Processing Potatoes.

Processing Grain.

Processing Tropical Raw Materials.

Mashing Processes Using Autoamylolytical Activities.

Yeast Mash Treatment.

Fermentation.

Distillation.

Stillage.

Analytical Methods.

Energy Consumption and Energy Balance in Classical Processes.

References.

\section{PART II.}

POTENTIAL SOURCE OF ENERGY AND CHEMICAL PRODUCTS (N. Kosaric \& F. VardarSukan).

Introduction.

Microbiology and Biochemistry of Ethanol Formation.

Immobilized Cell Systems.

Substrates for Industrial Alcohol Production.

Fermentation Modes of Industrial Interest.

Industrial Processes.

By-Products of Ethanol Fermentation.

Economic and Energy Aspects of Ethanol Fermentation.

Ethanol as a Liquid Fuel.

Present and Potential Markets for Ethanol.

Future Trends and Research.

References.

Subject Index.

*Editor's Note: The brief summary and the contents of the books are reported as provided by the author or the publishers. Authors and publishers are encouraged to send review copies of their recent books of potential interest to readers of Molecules to the Editor-in-Chief (Dr. Shu-Kun Lin, MDPI, Saengergasse 25, CH-4054 Basel, Switzerland. Tel. +41 79322 3379, Fax +41 61302 8918, E-mail: molinfo@mdpi.org). Some books will be offered to the scholarly community for the purpose of preparing full-length reviews.

(C) 2001 by MDPI (http://www.mdpi.org). 